\title{
Leveling kinetics of coatings with solvent evaporation and non-Newtonian rheology
}

\author{
Wang, Xueting; Huang, Yixin; Erik Weinell, Claus; Olsen, Stefan Møller; Kiil, Søren
}

Published in:

Progress in Organic Coatings

Link to article, DOI:

10.1016/j.porgcoat.2019.03.033

Publication date:

2019

Document Version

Peer reviewed version

Link back to DTU Orbit

Citation (APA):

Wang, X., Huang, Y., Erik Weinell, C., Olsen, S. M., \& Kiil, S. (2019). Leveling kinetics of coatings with solvent evaporation and non-Newtonian rheology. Progress in Organic Coatings, 132, 169-177.

https://doi.org/10.1016/j.porgcoat.2019.03.033

\section{General rights}

Copyright and moral rights for the publications made accessible in the public portal are retained by the authors and/or other copyright owners and it is a condition of accessing publications that users recognise and abide by the legal requirements associated with these rights.

- Users may download and print one copy of any publication from the public portal for the purpose of private study or research.

- You may not further distribute the material or use it for any profit-making activity or commercial gain

- You may freely distribute the URL identifying the publication in the public portal 


\title{
Leveling kinetics of coatings with solvent evaporation and non-
}

\section{Newtonian rheology}

\author{
Xueting Wang ${ }^{\mathrm{a}, 1}$, Yixin Huang ${ }^{\mathrm{a}, 2}$, Claus Erik Weinell ${ }^{\mathrm{a}, 3}$, Stefan Møller Olsen ${ }^{\mathrm{b}}$, Søren Kiil ${ }^{\mathrm{a}, *}$ \\ ${ }^{a}$ CoaST, Department of Chemical and Biochemical Engineering, Technical University of Denmark \\ (DTU), Building 229, 2800 Kgs. Lyngby, Denmark \\ ${ }^{1}$ E-mail: xewa@kt.dtu.dk \\ ${ }^{2}$ E-mail: yixin233@gmail.com \\ 33E-mail: cwei@kt.dtu.dk \\ bepartment of Fouling Release Systems, Hempel A/S, Lundtoftegårdsvej 91, 2800 Kgs. Lyngby, \\ Denmark \\ E-mail: stmo@hempel.com \\ Telephone: +4545933800
}

*Corresponding author, e-mail: sk@kt.dtu.dk, telephone: +45 45252827

Declarations of interest: none 


\begin{abstract}
In this work, two biocide-based antifouling (AF) coatings (a model and a full commercial system) were considered in a leveling study. Using an optical three-dimensional (3D) profilometer, an advanced rheometer, and evaporation rate measurements, the transient effects of wet film thickness, application wavelength, and coating viscosity on leveling could be investigated.

The model coating was able to level faster and had better final leveling performance than the commercial coating. This was attributed to the different viscosity profiles of the two coatings, the main difference being that the commercial coating contained additives (thixotropic and wetting agents) that affect the coating rheology.

A semi-empirical model, based on the so-called Orchard equation for ideal conditions, but modified here to take into account solvent evaporation and non-Newtonian rheology, was developed for the leveling kinetics. Due to the differences in rheological behavior for the two coatings considered, adjustable model parameters needed to be fitted for each coating case. Overall, viscosity build-up was found to be the dominating parameter for leveling.
\end{abstract}

\title{
Keywords
}

Leveling; coating; viscosity; film thickness; wavelength; solvent evaporation

\section{List of symbols}

$t$

$a_{t}$
Time (s)

Amplitude at time $t(\mathrm{~m})$ 


\section{Greek symbols}

$$
\beta
$$$$
\gamma
$$

$\sigma$

$\eta$

\section{Subscripts}

Amplitude at time 0 (m)

The average film thickness (m)

Waviness at time $t(\mathrm{~m})$

Waviness at time $0(\mathrm{~m})$

Exponent for the average film thickness

Exponent for the wavelength

Exponent for the viscosity

Constant $\left(\mathrm{m}^{\mathrm{b}-\mathrm{a}-\mathrm{c}} \cdot \mathrm{kg}^{\mathrm{c}} \cdot \mathrm{s}^{-\mathrm{c}-1}\right)$

Exponent for the viscosity

Constant $\left(\mathrm{kg}^{\mathrm{e}} \cdot \mathrm{m}^{-\mathrm{e}} \cdot \mathrm{s}^{-\mathrm{e}-1}\right)$

Constant $\left(\mathrm{m}^{-\beta}\right)$

Constant $\left(\mathrm{m}^{-\gamma}\right)$

The sum of squared residuals

The number of experimental data sets

Exponent for the average film thickness

Exponent for the wavelength

Surface tension $(\mathrm{N} / \mathrm{m})$

$\underline{\text { Viscosity }(\mathrm{Pa} \cdot \mathrm{s})}$

Slettet: The v

Structure wavelength (m)

Slettet: The s 


$\begin{array}{ll}\min & \text { minimum } \\ \exp & \text { from experiments } \\ \text { model } & \text { from model }\end{array}$

\section{Introduction}

The appearance and performance of coatings depend on the ability of the coating to level. One example is orange peel after spraying application, where a wavy coating texture (similar to the surface of an orange) can result from unbalanced coating formulation or spray conditions [1]. This affects the esthetic appearance of coatings and constitutes sites of potential weakness, which may harm the coating performance [2,3]. Another example is fouling control coatings (FCCs) on ship hulls where the coating surface must be smooth to lower skin friction and the associated fuel consumption. A non-smooth surface also leads to more biofouling [4].

\subsection{Leveling studies of coatings}

The importance of leveling for surface protection was early recognized and leveling of coatings has been studied since the 1920s. However, progressing the understanding of the mechanisms and the influencing factors of leveling has been slow [2]. In 1961, the leveling phenomenon was investigated by Smith, Orchard, and Rhind-Tutt through brush mark studies [5]. Two years later, a systematic study of leveling was published by Orchard [6], wherein he proposed a rate equation which later became known as the so-called Orchard equation:

$$
\ln \left(\frac{a_{t}}{a_{0}}\right)=-\frac{16 \pi^{4} \sigma h^{3}}{3 \lambda^{4} \eta} t
$$


where, $a_{t}$ and $a_{0}$ represent amplitudes of surface 'waves' at time $t$ and time zero, respectively. $\sigma$ is the coating surface tension, $h$ represents the average film thickness, $\lambda$ is the application wavelength, and $\eta$ is the coating viscosity. He proposed that surface tension is the dominant driving force for leveling when the wavelength is less than one $\mathrm{cm}[6]$.

Orchard, as a basis for his equation, assumed a sinusoidally structured coating surface on a smooth substrate as illustrated in figure $\mathbf{1}$.

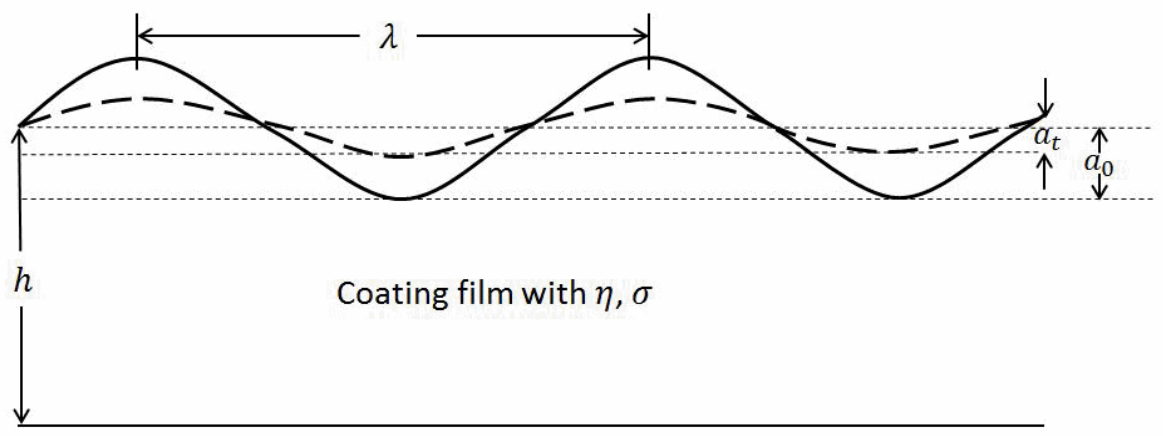

Figure 1. Schematic illustration of a sinusoidally structured coating film. The solid line (wavy curve) represents the initial coating surface with amplitude $a_{0}$ and the dashed line (wavy curve) represents the coating surface with amplitude $a_{t}$ after leveling time $t . h$ is the average film thickness, $\lambda$ is the application wavelength, $\eta$ is the coating viscosity, and $\sigma$ is the surface tension of the coating film, respectively.

The Orchard equation was derived assuming that the average film thickness, the application wavelength, and the coating viscosity do not change over time. This, of course, is unrealistic for coatings containing solvents that evaporate during and after application. The surface tension was also assumed to be constant, which is in good agreement with the work of Smith and co-workers [5], and 
Overdiep [7] and Seeler [8], who found that surface tension in practice typically only changes a few percent over the course of leveling. One thing to notice, is that the Orchard equation (because of the assumption of no evaporation and Newtonian liquid) predicts that with time, an entirely smooth surface is formed ( $a_{t}$ goes to zero, when $t$ goes to infinity), which is not useful for practical coating applications, where this performance is not achieved.

Coating viscosity is probably the most important parameter for leveling. In practice, it will vary from the initial liquid coating viscosity and gradually increase and essentially become infinite as the coating changes from a viscoelastic liquid to a viscoelastic solid. This happens due to solvent evaporation and/or chemical curing of the coating. Coating viscosity is also a function of shear which changes from high shear during application to much lower shear during leveling. The thixotropic (time-dependent shear thinning) effect complicates the viscosity behaviors during leveling even more. In addition, due to solvent evaporation, the average film thickness decreases over time. It is perhaps not surprising, that Overdiep [7] could demonstrate that the Orchard equation failed, even qualitatively, to describe leveling of solvent-based alkyd coatings.

Wilson, based on the Overdiep model, continued the development work on models for coating films [9-11]. Various numerical models were developed based on the so-called lubrication theory, a timedependent solution of the Navier-Stokes equations [12-16]. In those models, two assumptions were needed: 1) the amplitude is small relative to the average film thickness, and 2) the wavelength is long relative to the average film thickness. Various effects were included in the models, such as gravitational pull, surface tension gradient effects (also known as Marangoni effects) arising from nonuniformities in the local concentration of solvent [10], and non-Newtonian effects. However, the models only included one or a couple of those effects [8]. Overall, it has been a challenge to cover all phenomena in one model. 
In previous investigations $[3,7,17]$, measurements of leveling were not quantitative and most of the approaches were designed for certain specialized types of coatings such as alkyd coating, spin coating, or powder coating. Bosma et al. [18], however, developed a method for estimation of leveling behavior of powder coatings in a quantitative manner. In the same year, the evolution of surface texture in automotive coatings was investigated in details by Peters et al. [19], where Newtonian flow without solvent evaporation, Newtonian flow with solvent evaporation, and viscoelastic coatings with nonNewtonian behavior were studied separately, using model liquids and commercial coatings. They found that the evolution of surface texture was strongly correlated to temperature and solvent content.

\subsection{Strategy of investigation}

In the present investigation, the new approach developed in our earlier work (Wang et al. [20]), was used to study leveling. The technique involves a combination of an automatic spiral-drawdown application and a 3D measurement system based on an optical profilometer. With this macroscopic approach, a well-defined sinusoidal surface structure can be generated on the coating surface, thereby allowing the effects of important physical parameters (average film thickness, application wavelength, and coating viscosity) on leveling to be systematically studied. Furthermore, by combining the macroscopic approach with separate measurements in an advanced rheometer, dynamic data for waviness, average film thickness, wavelength, and viscosity could be collected non-destructively during leveling process. As a consequence, it was possible to quantify the leveling kinetics of coatings with solvent evaporation and non-Newtonian rheology.

As a case study for the investigations, a fouling control coating (FCC) was selected. More specifically, we used a conventional biocide and solvent-based antifouling (AF) coating type which we have 
described in our previous work [4]. FCCs are applied as top layers on ship hulls to prevent biofouling growth and thereby to limit drag resistance [21]. A rough FCC surface can increase the frictional resistance and constitute sites of weakness, i.e., potential starting points for corrosion, cracking, blistering and biofouling [22,23]. The reason for choosing an AF coating is that it presents a rather wavy coating surface, which gives rise to a higher drag force than for so-called fouling release coatings [4],due to the high pigment volume concentration (> about 40\%), In addition,, it cures by physical drying only (no crosslinking),

Both waviness (macro-roughness) and roughness (micro-roughness) can have an influence on the measured drag of a surface, but we assume in this work ('smooth coatings') that the waviness is the dominating factor. An investigation in support of this is provided in the work of Townsin et al. (1981), who found that the drag of a roughened propeller in service was strongly dependent on the wavelengths above $0.8 \mathrm{~mm}$ (an increase in the drag of over $50 \%$ was seen when the cut-off wavelength was increased from 0.8 to $2.5 \mathrm{~mm}$ and a change of 100 percent in drag resulted from reducing the cut-off wavelength to $0.25 \mathrm{~mm}$ ). Anyway, the analysis of this work is concerned with quantification of coating leveling and not drag force measurements of FCCs, which are provided elsewhere [4,24,25].

\section{Materials and methodology}

\subsection{Equipment}

Surface measurements of coatings, after film application on acrylic panels with a retrofitting commercial film applicator (Coatmaster from Erichsen), were conducted using an optical 3D profilometer from KEYENCE with VR-3100 sensor head. Viscosity measurements were performed using a Discovery Hybrid Rheometer (DHR-2) from TA Instruments. Detailed descriptions for both
Kommenterede [SK1]: Should we change "rough" to "nonuniform" here? Then we have not specified if we mean roughness or waviness. If we write "rough", I think we contradict ourselves in the introduction.

Slettet: rough

Slettet:

Slettet: and

Kommenterede [SK2]: Why do we mention this? Because it simplifies the analysis?

Slettet: 
equipment and uncertainty analysis can be found in our previous work (Wang et al. [20]). Equipment uncertainty for waviness measurements using the profilometer was about $3 \%$.

Spiral rod applicators with different dimensions, see figure 2, were tailor-made and used in the experiments. The spiral applicators provided well-defined sinusoidal surface geometries and ensured various initial wet film thicknesses and wavelengths. For the sinusoidal geometry, the wavelength was defined by the gap between two spiral wires. The initial wet film thickness was controlled by the depth of the grooves between two wires which was determined by the size of the wires, the larger the wire, the larger the grooves. All applicators were made of stainless steel-316.

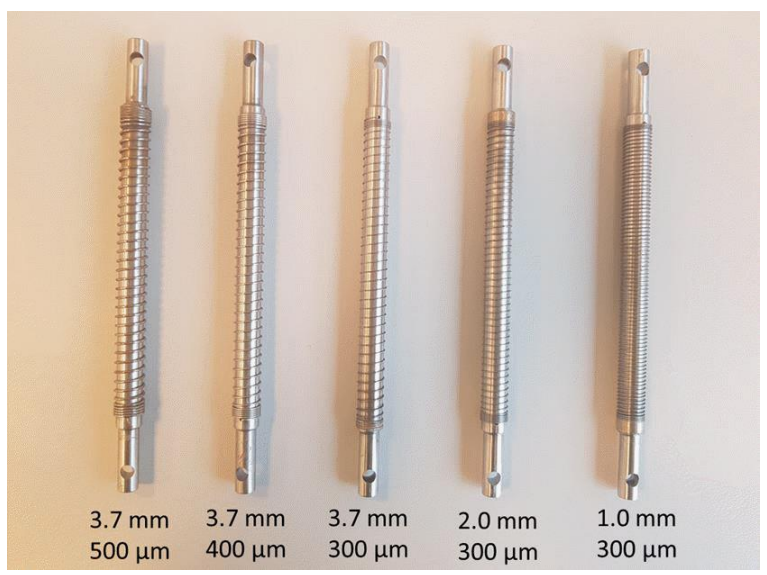

Figure 2. Spiral applicators with different dimensions of application wavelength and targeted initial wet film thickness.

\subsection{Materials}

A commercial AF coating (Globic 9000 78950) and two model AF coatings were used in the investigations. The two model AF coatings were prepared based on a simplified reference formulation 
which was formulated based on commercial AF coatings. The composition of the simplified reference formulation is shown in table $\mathbf{1}$. The two model coatings had higher solvent contents than the reference formulation; sample S1 $26.9 \mathrm{wt} \%$ and sample S2 $27.6 \mathrm{wt} \%$.

The raw materials were all supplied by Hempel A/S. Coatings were produced using high-speed dispersion. During coating sample preparation, the fineness of grind was targeted to $40 \mu \mathrm{m}$.

To investigate the effects of viscosity on leveling, coating samples with different solvent contents (31, $29,28,27,25$, and $24 \mathrm{wt} \%$ ) were prepared based on sample S1 to give different initial viscosities.

Table 1. Composition of a simplified reference AF coating formulation.

\begin{tabular}{cc}
\hline Ingredients & Concentration (wt\%) \\
\hline Xylene/Dimethylbenzene & 20 \\
Methyl isobutyl ketone solvent & 4 \\
Zinc oxide & 10 \\
Bentonite & 2 \\
Talc & 12 \\
Cuprous oxide & 24 \\
Gum rosin & 18 \\
Acrylic binder & 10 \\
\hline
\end{tabular}

\subsection{Methodology}

\section{Surface measurements (waviness and wavelength measurements)}

The detailed operational procedure for surface measurements using the film application system and profilometer, as well as how to separate roughness and waviness based on choosing proper cut-off lengths, can be found in our previous work [20]. Here will only be given a concise description. 
The waviness parameter, $W a$ (the average height for waviness profile of multiple defined lines in the scanned sampling area), was used to evaluate the leveling performance. The calculating methodology used for Wa complies with International Organization for Standardization (ISO) standards [26,27]. To obtain the waviness profile, cut-off length values of $2.5 \mathrm{~mm}$ and $0.8 \mathrm{~mm}$ were applied for coating surfaces generated from spiral applicators with wavelengths of $3.7,1$ or $2 \mathrm{~mm}$, respectively. Meanwhile, the wavelength changes during leveling could also be obtained from the transient surface (waviness) measurements.

\section{Average film thickness measurements}

The average film thickness decrease, due to solvent evaporation, was directly measured using the profilometer. The same application procedure as for the surface measurements was used. Then the coated panel was placed at a location where the edge of the coating film could be scanned by the profilometer as shown in figure $\mathbf{3}$ (left). Subsequently, the average film thickness was measured from the surface profile (figure 3, right). Thus, transient average film thickness values during solvent evaporation and the leveling process were obtainable from the same location at different times after film application.
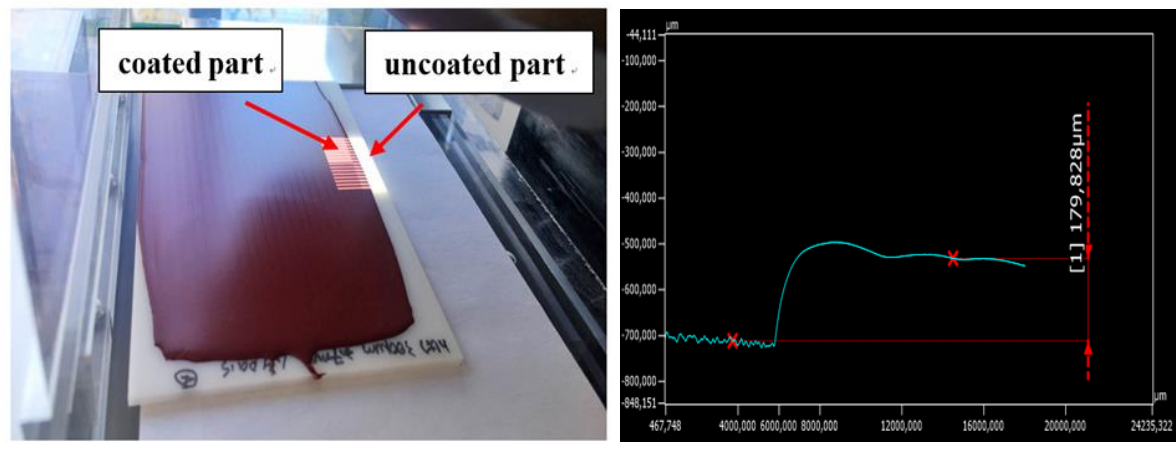
Figure 3. The average film thickness measurement after application (left) and an example of a measurement series obtained from the surface profile (right) at a given point in time. In the figure to the right, the average film thickness was estimated to about $180 \mu \mathrm{m}$, as indicated in the figure.

\section{Evaporation rate experiments}

To obtain solvent evaporation profiles, separate evaporation rate experiments were performed. The coating films were applied under the same conditions as those used in the surface measurements to simulate the solvent evaporation process during surface measurements. Immediately after coating application and onwards, the coated panels were weighed using a precision balance (ENTRIS 623I-1S from Sartorius with an accuracy of $0.001 \mathrm{~g}$ ). For each sample, the same procedure was repeated three times.

\subsubsection{Experimental procedure for studying effects of individual physical parameters on leveling}

The following experimental procedures were performed to study the effects on leveling of coating sample S1 of different individual physical parameters, including the initial wet film thickness, the application wavelength, and the coating viscosity. All coating applications were performed horizontally. The effects of the substrate on the coating leveling was not investigated. All the experiments were done with acrylic panels with a surface roughness of about $6 \mu \mathrm{m}$.

To investigate the effects of the initial wet film thickness, film applications with different spiral applicators $(300,400$, and $500 \mu \mathrm{m})$ with the same initial wavelength $(3.7 \mathrm{~mm})$ were conducted. Immediately after each application, the surface measurement was initiated. Three repetitions were done for the initial wet film thickness of $300 \mu \mathrm{m}$. 
To investigate the effects of the application wavelength, film applications with different applicators (1, 2, and $3.7 \mathrm{~mm}$ ) with the same initial wet film thickness $(300 \mu \mathrm{m})$ were performed. The same experimental procedure was repeated three times for each wavelength.

The effects of viscosity on leveling were studied using coating samples with different solvent contents $(31,29,28,27,25$, and $24 \mathrm{wt} \%)$. The viscosity of each sample was measured using a DHR-2 rheometer under the same constant shear rate of $117.4 \mathrm{~s}^{-1}$ (similar to the shear rate generated from a KU-1 Viscometer from Brookfield as used in industry). Thixotropic behavior was observed for all coating samples, when examined on the rheometer. The film application for each sample was performed using the spiral applicator with a wavelength of $3.7 \mathrm{~mm}$ giving an initial wet film thickness of $300 \mu \mathrm{m}$. Following application, the surface measurement was performed for each sample. For two coating samples, the film application and surface measurement procedure were repeated three times.

Separate evaporation rate experiments were conducted for coating samples with solvent contents of 29, 27 , and 24 wt $\%$ to further understand the effects of viscosity on leveling. For each sample, two repetitions were performed.

\subsubsection{Collection of experimental data series for model development}

Using the spiral applicator with a wavelength of $3.7 \mathrm{~mm}$, all coating samples were applied on acrylic panels aiming at an initial wet film thickness of $300 \mu \mathrm{m}$. After application, changes in waviness $(W a)$, wavelength, and average film thickness were obtained in the same ways as in the aforementioned "surface measurements" and "average film thickness measurements" sections. Both surface measurements (for obtaining waviness and wavelength values) and average film thickness measurements were repeated five times for sample $\mathrm{S} 2$ and three times for the commercial AF coating. 


\section{Viscosity measurements}

The solvent contents of applied coatings, corresponding to different experimental times during a leveling experiment, were obtained from the solvent evaporation rate experiments (using approximately the same film thickness, application method, and laboratory air conditions for leveling and evaporation). Subsequently, these solvent content-time data sets (see Table 2 for an example) enabled the formulation of a series of separate coating samples with the exact same solvent contents as those observed in the time series, which could then be used for viscosity measurements at a constant shear rate corresponding to leveling. In other words, it was (approximately) possible to follow the viscosity development of a given coating during simultaneous leveling and solvent evaporation. However, one limitation for the coatings considered was that the prepared samples could only cover the coating conditions within the initial 8.5 minutes after application because of too high viscosity values at later times (where the coating went from a viscoelastic liquid to a viscoelastic solid).

Table 2. Samples prepared for viscosity measurements and their corresponding solvent contents at different times during leveling of sample S2 after application.

\begin{tabular}{ccc}
\hline Sample No. & Time after application (s) & Solvent content (wt\%) \\
\hline 1 & 0 & 27.55 \\
2 & 50 & 27.02 \\
3 & 95 & 26.46 \\
4 & 130 & 26.00 \\
5 & 225 & 24.94 \\
6 & 330 & 23.97 \\
7 & 429 & 21.98 \\
8 & 510 & 21.00 \\
\hline
\end{tabular}

Initially, sample 1 with the highest solvent content $(27.55 \mathrm{wt} \%)$ was prepared. Then sample 1 was divided into eight containers and seven of them were subjected to intensive solvent evaporation at room 
temperature by manually stirring the coatings on the balance until the desired solvent content was reached (the weight was monitored during this process).

Subsequently, the viscosities of the coating samples were measured using the DHR-2 rheometer with two steps of flow peak hold tests: the first step with high shear rate $\left(10^{3} \mathrm{~s}^{-1}\right)$ representing the application process; followed immediately by the second step with low shear rate $\left(10^{-2} \mathrm{~s}^{-1}\right)$, representing the leveling process. Each sample was measured three times. Thixotropic and shear-thinning behaviors were observed for all coating samples. Based on the transient viscosity curves obtained during the low shear rate period, the viscosity value at the targeted time was adopted for each sample to represent the corresponding transient viscosity during the leveling process, in accordance with the surface (waviness) measurements.

It should be mentioned that uncertainties exist in the approach of obtaining transient viscosity values during leveling. The obtained viscosity values may not exactly represent the real viscosities during leveling due to the unknown corresponding shear rates at different times after application. During the leveling procedure, the coating might experience lower shear rates than the value used in the viscosity measurements $\left(10^{-2} \mathrm{~s}^{-1}\right)$. Moreover, rheometer results showed that the shear stress was increasing during the measurement because viscosity was increasing when the shear rate was controlled to be constant. However, the shear stress should be decreasing during leveling after the sudden removal of application where high shear stress was imposed to the coating [8]. Thus, there are limitations in obtaining correct viscosity values during leveling.

In summary, experimental series of coupled values of waviness $(W a)$, application wavelength $(\lambda)$, average film thickness $(h)$, and coating viscosity $(\eta)$ were collected at different times $(t)$ during leveling. These data series were subsequently used in the development of the semi-empirical leveling equation. 


\subsubsection{Development of leveling model}

The complexity of the leveling process, when solvent evaporation takes place and film thickness and coating viscosity change over time, is high. In this case, to capture the leveling process in one single equation requires a semi-empirical approach. Due to the lack of scientifically-based alternatives, a semi-empirical model based on the Orchard equation was used as shown below.

$$
\ln \left(\frac{a_{t}}{a_{0}}\right)=-\frac{16 \pi^{4} \sigma h^{3}}{3 \lambda^{4} \eta} t \Rightarrow \ln \left(\frac{W a_{t}}{W a_{0}}\right)=d \frac{h(t)^{a}}{\lambda(t)^{b} \eta(t)^{c}} t
$$

Notice, that the amplitude, $a_{t}$ and $a_{0}$, have been replaced by the waviness, $W a_{t}$ and $W a_{0}$. Besides, as explained in the introduction section, surface tension $\sigma$ does not undergo significant changes during solvent evaporation and has, together with the other constants, been lumped into the constant $d . a, b$, and $c$ are new exponents for average film thickness, wavelength and viscosity.

Using minimization of the sum of least squares (eq. 3), the exponent of each individual physical parameter could be estimated.

$$
S_{\text {min }}=\sum_{i=1}^{n}\left[\ln \left(W a_{t} / W a_{0}\right)_{\text {exp }}-\ln \left(W a_{t} / W a_{0}\right)_{\text {model }}\right]^{2}
$$

The 'fmincon' solver of MATLAB was used for actual implementation. The values of $a, b$, and $c$ were constrained to positive values and the value of $d$ was constrained to be negative because the natural logarithm term of the model (as written in eq. 2) was always negative.

\section{Results and discussion}

The effects of initial wet film thickness, application wavelength, and coating viscosity on leveling of coatings with solvent evaporation were investigated and will be presented in the coming paragraphs. Subsequently, the semi-empirical model is used to describe the leveling process. 


\subsection{Effects on leveling of initial wet film thickness}

The effects of different initial wet film thicknesses on leveling of sample S1 are shown in figure 4 [28]. It can be seen that the very first $W a$ value measured decrease when the initial wet film thickness is increased, which suggests that a higher film thickness results in a more adequate flow around the spiral applicator and provides better leveling result. However, compared to their initial $W a$ values, the final $W a$ values dropped respectively 56,62 , and $50 \%$ for initial wet film thickness of 300,400 , and $500 \mu \mathrm{m}$. Thus, no clear trend was found for the effects of initial wet film thickness on the leveling rate based on the obtained data. Nevertheless, we think it is possible that the initial $W a$ value at time zero, which was not measurable with the present equipment (one measurement takes $15 \mathrm{~s}$ ), could be proportional to the depth of the grooves on the spiral applicator, which thereby defines the initial wet film thickness. In other words, the initial $W a$ value at time zero could be higher when the initial wet film thickness is higher. Consequently, the initial leveling rate (the slopes between the first data point and the value at time zero) may increase with the initial wet film thickness. However, this could not be confirmed.

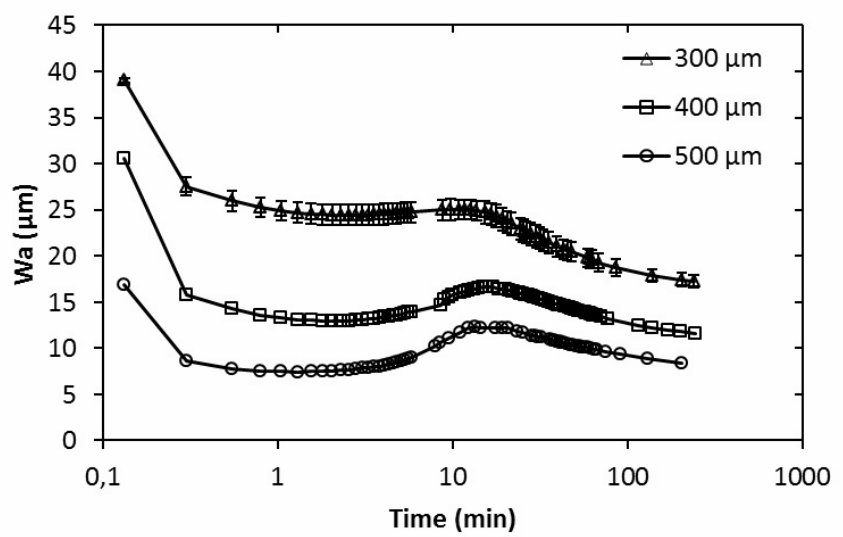


Figure 4. Transient waviness $(W a)$ values over time after drawdown application for different initial wet film thicknesses $(300,400$, and $500 \mu \mathrm{m})$. The error bars shown for $300 \mu \mathrm{m}$ case represent the standard deviations from three repetitions. Notice that the $\mathrm{x}$-axis is in logarithmic scale to emphasize the curve development immediately after application.

The slight increase in the $W a$ value after about $10 \mathrm{~min}$ (also seen in figures $\mathbf{5}$ and $\mathbf{6}$ ) can be attributed to the fast solvent loss, which increased the amplitudes of the peaks and valleys, according to the waviness (amplitude) profiles obtained over the drying process. All waviness (amplitude) profiles corresponded well with the changes of the $W a$ values (a detailed discussion is provided in [20]). The so-called 'reversal' phenomenon (Marangoni effect) [10] was not observed for any of the samples.

\subsection{Effects on leveling of application wavelength}

The effects on leveling of different initial wavelengths of the sinusoidal surface, generated with the spiral applicators, are presented in figure 5 [28]. It can be seen that waviness, $W a$, increases with wavelength, which means a larger wavelength leads to a worse leveling result. For the $1 \mathrm{~mm}$ case, the captured initial waviness is already so low due to the initial fast leveling rate, that further leveling does not seem possible. 


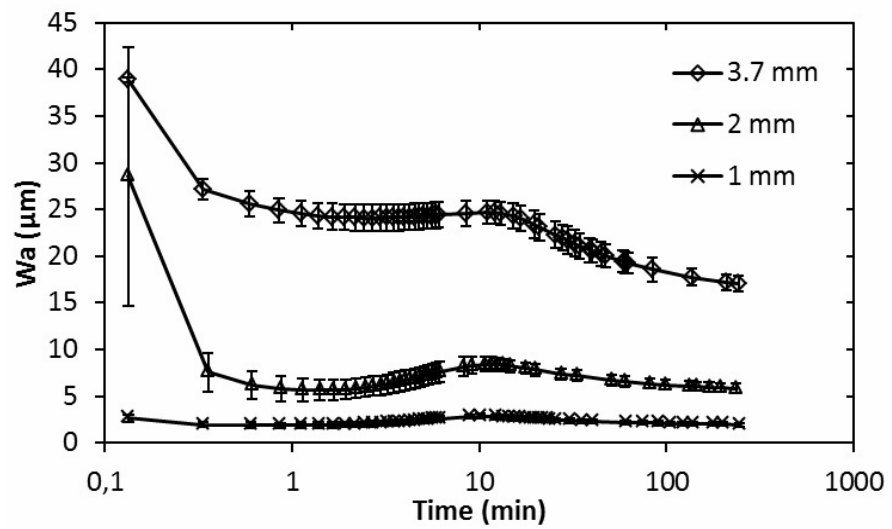

Figure 5. Transient waviness $(W a)$ values over time after drawdown application with different initial wavelengths of the sinusoidal surface $(1,2$, and $3.7 \mathrm{~mm})$. Each data point is the average value of three repetitions and the error bars shown represent the standard deviation. Notice that the $\mathrm{x}$-axis is in logarithmic scale to emphasize the curve development immediately after application.

\subsection{Effects on leveling of coating viscosity}

The viscosities measured of the samples with different solvent contents were 1.06, 1.68, 2.27, 4.09, 6.52, and 8.56 Pa.s under a shear rate of $117.4 \mathrm{~s}^{-1}$. Normally, the viscosity we see of commercial AF coatings is about $0.95-2.2 \mathrm{~Pa} \cdot \mathrm{s}$ at this shear rate.

The effects of those initial coating viscosities on leveling are shown in figure 6 [28]. It can be seen that the waviness, $W a$, increases with viscosity. Notice, that the spectrum of the $W a$ value is very broad. Moreover, all samples behave in a similar way except the one with the highest viscosity (8.56 Pa.s). The initial decrease of $W a$ was not observed for the sample with a viscosity of $8.56 \mathrm{~Pa} \cdot \mathrm{s}$. 


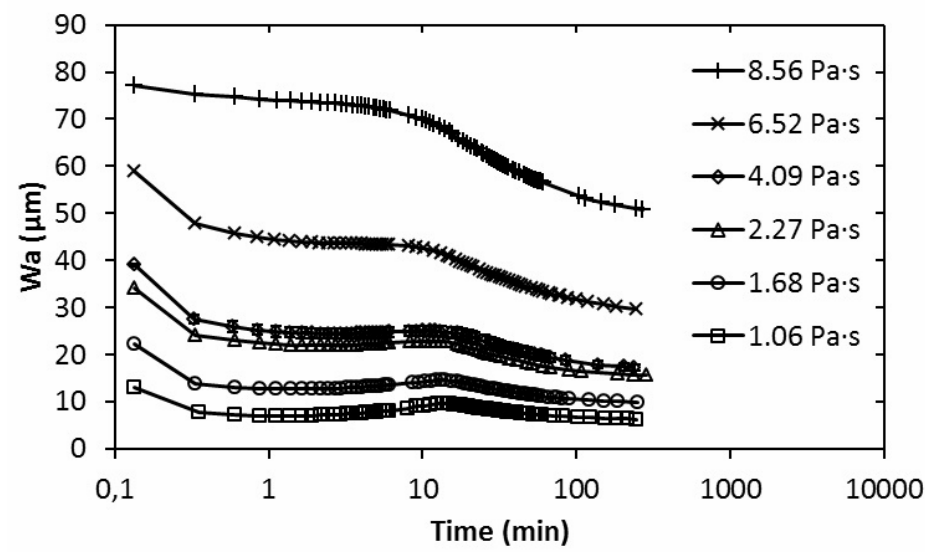

Figure 6. Transient waviness $(W a)$ values over time after drawdown application for coating sample S1 with different initial viscosities $(1.06,1.68,2.27,4.09,6.52$, and $8.56 \mathrm{~Pa} \cdot \mathrm{s})$. The error bars shown for 4.09 $\mathrm{Pa} \cdot \mathrm{s}$ case represent the standard deviations from three repetitions. They are too small to be seen. Notice that the $\mathrm{x}$-axis is in logarithmic scale to emphasize the curve development immediately after application.

The effects of viscosity on leveling can be further demonstrated with the aid of solvent evaporation rate experiments. Results, for selected samples with initial viscosities of $1.68,4.09$, and $8.56 \mathrm{~Pa} \cdot \mathrm{s}$, are shown in figure 7 [28]. The viscosity development is coupled to the two distinct evaporation rate regimes; an initial fast evaporation rate period, where external solvent mass transport controls the rate, followed by a much slower evaporation rate period, where internal solvent diffusion in the coating dominates [29]. It can be seen that the sample with the lowest initial viscosity has the longest constant evaporation rate period (10 minutes versus 7 and 5 minutes for 4.09 and $8.56 \mathrm{~Pa} \cdot \mathrm{s}$ ), corresponding to the longest time before 'skin' forms on the surface of the coating at which point the viscosity increases 
rapidly and the leveling rate goes down. Hence, it confirms that the leveling is retarded by the increased viscosity resulting from solvent evaporation.
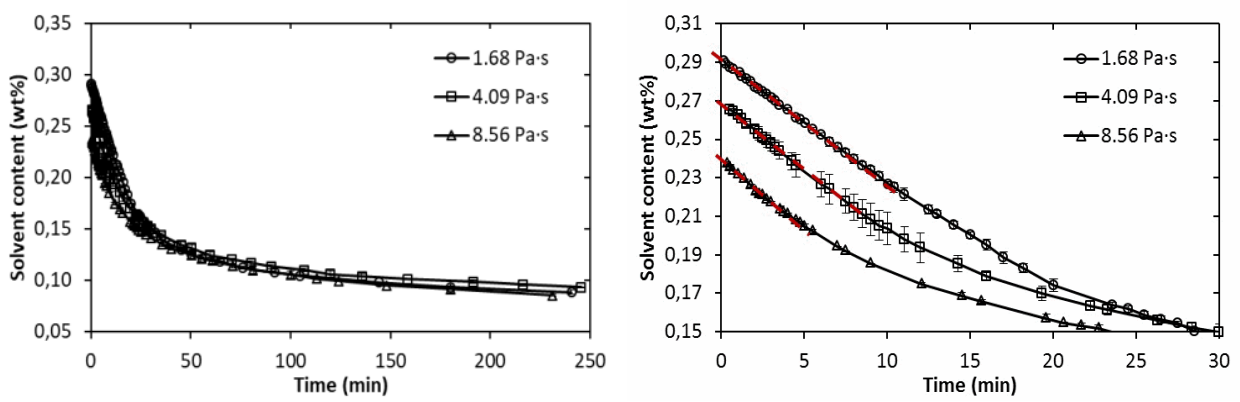

Figure 7. Solvent content over time during evaporation rate experiments for coating sample S1 with three different initial viscosities (solvent contents): $1.68 \mathrm{~Pa} \cdot \mathrm{s}$ (29 wt\%), 4.09 $\mathrm{Pa} \cdot \mathrm{s}(27 \mathrm{wt} \%$ ), and 8.56 $\mathrm{Pa} \cdot \mathrm{s}(24 \mathrm{wt} \%)$. The plot on the right hand side shows more details within the initial 30 mins. The red dashed lines indicate the initial constant evaporation rate period. Each data point is the average value of two repetitions and the error bars shown represent the standard deviations (most of them are too small to be seen).

Due to the presence of solvent concentration and curing degree profiles in thermoset coatings [29], it should be noted that viscosity and shear stress will most likely also be functions of position in the coating. However, such a detailed level of analysis is not possible with the present equipment.

\subsection{Simultaneous tracking of solvent content, film thickness, viscosity, wavelength and waviness}

The full experimental series of coating parameters within the first seven minutes after application are summarized in figure 8 [28] for the model coating (S2) (left) and the commercial AF coating (right). 
It can be seen that during the leveling process, the wavelength value did not change much and only small fluctuations around the expected value $(3.7 \mathrm{~mm})$ were observed for the model coating. Moreover, it was found that the average film thickness decreased (about 10-12\%) linearly with time (about $3.7 \mu \mathrm{m}$ per minute) within this time span (as shown in figure 9 [28], the film thickness reached a plateau after a couple of hours). The solvent content curve exhibits a similar trend, which is reasonable because the reduction of average film thickness is directly related to the solvent evaporation.

Compared to the results of the coating sample S2 (see figure 8), the waviness values of the commercial coating were much higher and the final leveling result was poorer than for sample S2. Furthermore, the viscosity build-up of the commercial coating was very different. This, most likely, is because the overall solvent contents of the commercial coating (from 16 to $19 \mathrm{wt} \%$ ) were lower than those of sample S2 (23-27.5 wt\%). For sample S2, the viscosity value was $1465 \mathrm{~Pa} \cdot \mathrm{s}$ when the solvent content was $22 \mathrm{wt} \%$, which means that the viscosity would be even higher when the solvent content was lower than $19 \mathrm{wt} \%$. However, for the commercial coating, the viscosity was $83 \mathrm{~Pa} \cdot \mathrm{s}$ when the solvent content was $19 \mathrm{wt} \%$. The reason why the commercial coating could have such low viscosity at the same solvent content as the model sample S2 was most likely that the additives inside the commercial coating (thixotropic and wetting agents) imposed rheological effects to the coating. This was probably also responsible for the difference in viscosity build-up. Consequently, the poor leveling performance could be attributed to the viscosity development. Overall, the coating viscosity was found to be the dominant parameter affecting the leveling process, because viscosity showed the largest changes (increased about $2379 \%$ for S2 and $1940 \%$ for the commercial coating) among all parameters during the leveling process. 

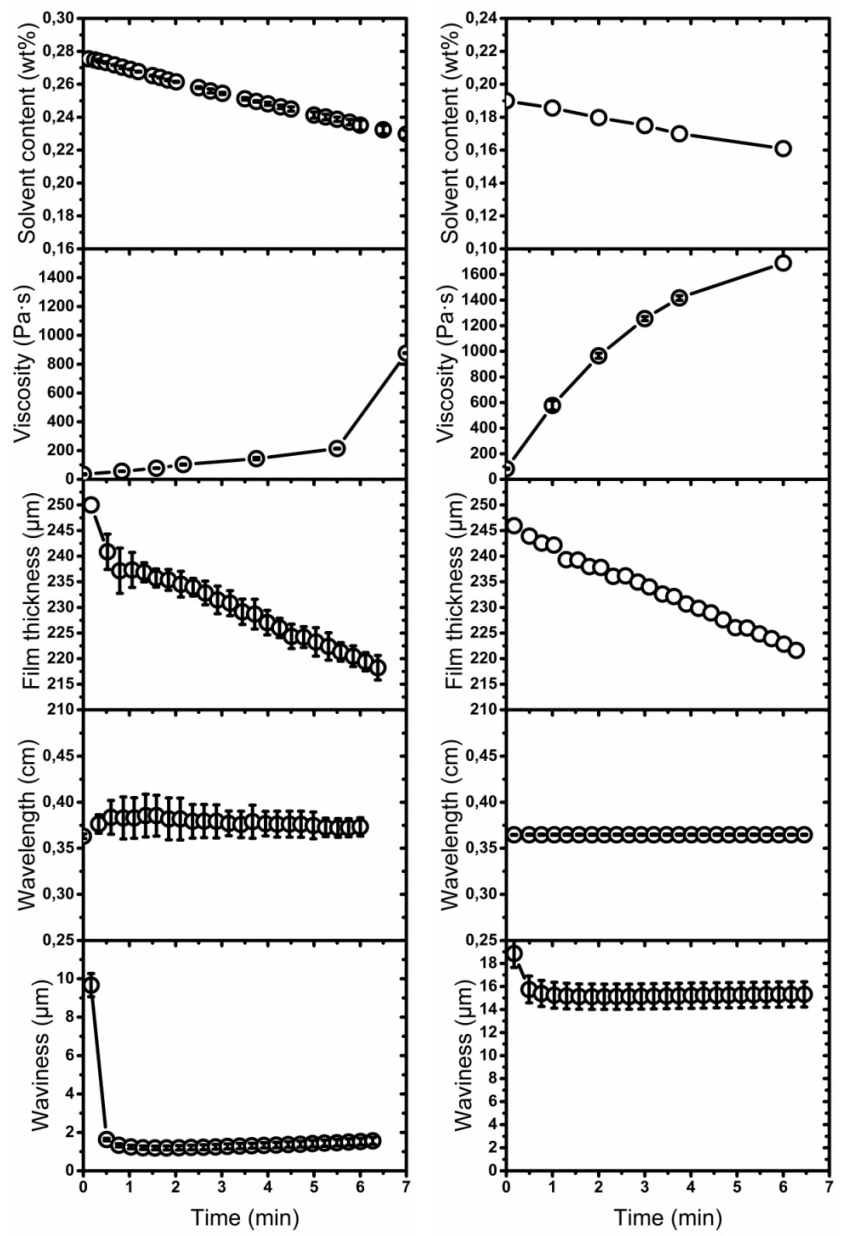

Figure 8. The transient process of solvent evaporation and leveling for the model coating S2 (left) and the commercial antifouling (AF) coating (right). The coating parameters followed were (from top to bottom): solvent content, coating viscosity, average film thickness, application wavelength, and waviness. Each data point is an average value except for solvent content and film thickness in the right hand plot. The error bars shown represent the standard deviations of repetitions. 


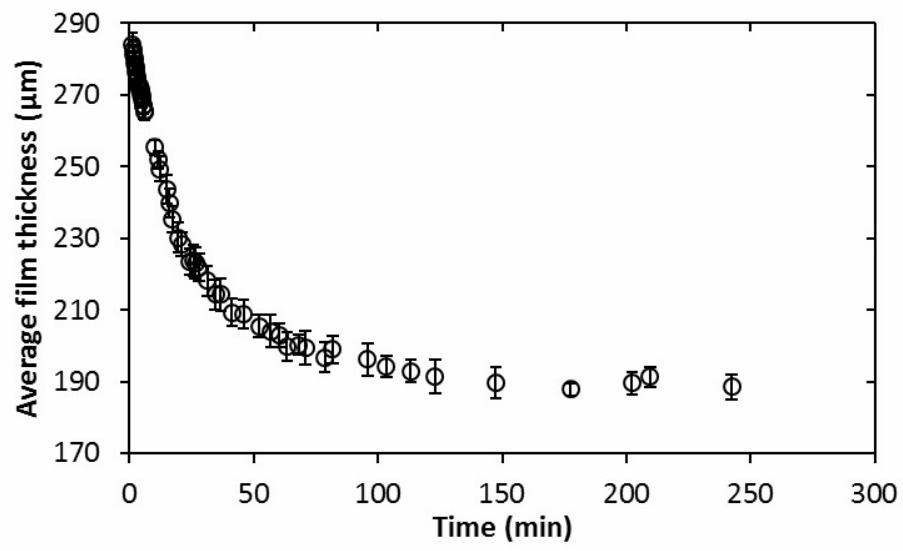

Figure 9. Average film thickness over time for sample S1 after application using the spiral drawdown applicator giving $300 \mu \mathrm{m}$ initial average film thickness with $3.7 \mathrm{~mm}$ wavelength.

\subsection{Development of semi-empirical model for leveling}

\subsubsection{Relationship between final leveling performance and initial coating parameters}

The relationships between final leveling performance and the initial coating parameters (film thickness and wavelength) were correlated based on the experimental results shown in figure $\mathbf{4}$ and $\mathbf{5}$. To correlate the final waviness values with the different initial film thicknesses, the following relationship was proposed

$$
\frac{W a_{t}}{W a_{0}}=E h^{\beta}
$$

where $E$ is a constant. The exponent $\beta$ for the film thickness dependency can be estimated from the slope of a plot of $\ln \left(W a_{t} / W a_{0}\right)$ against $\ln (h)$. For correlating the final waviness values with the different initial wavelengths, a similar relationship was used: 


$$
\frac{W a_{t}}{W a_{0}}=E^{\prime} \lambda^{\gamma}
$$

where $E^{\prime}$ is a constant and the exponent $\gamma$ for the wavelength can be estimated from the slope of a plot of $\ln \left(W a_{t} / W a_{0}\right)$ against $\ln (\lambda)$. The empirical models obtained are shown in eq. (6) and (7) [28]:

$$
\begin{aligned}
\frac{W a_{t}}{W a_{0}} & =\left(975787 \mu m^{2.77 \pm 0.024}\right) h^{-2.77 \pm 0.024} \\
\frac{W a_{t}}{W a_{0}} & =\left(0.015 \mathrm{~mm}^{-1.68 \pm 0.030}\right) \lambda^{1.68 \pm 0.030}
\end{aligned}
$$

The correlation coefficients for eq. (6) and (7) were 0.9999 and 0.9997 , respectively. Equation (6) and (7) are valid when the film thickness $h$ is within $300-500 \mu \mathrm{m}$ and the wavelength is within $1-3.7 \mathrm{~mm}$ for coating sample S1, respectively. The two equations can be used for estimating and comparing the waviness decay or final leveling performance of a similar coating with different initial film thicknesses and wavelengths, respectively.

\subsubsection{Transient model fitting}

According to the experimental data provided in figure 8, the application wavelength is practically constant during leveling process. In addition, the film thickness change is also very little (about 10$12 \%$ ). On the other hand, viscosity changes $2379 \%$ (1940\% for the commercial coating). Therefore, the viscosity was assumed to be the only important parameter during solvent evaporation and leveling and the semi-empirical model of eq. (2) was adjusted to the following model.

$$
\ln \left(\frac{W a_{t}}{W a_{0}}\right)=d \frac{h(t)^{a}}{\lambda(t)^{b} \eta(t)^{c}} t \Rightarrow \ln \left(\frac{W a_{t}}{W a_{0}}\right)=\frac{f}{\eta(t)^{e}} t
$$

where the film thickness term, $h(t)^{a}$, and the wavelength term, $\lambda(t)^{b}$, were lumped into a new constant $f$. Consequently, the semi-empirical model of eq. (8) was fitted to the transient experimental data of waviness and viscosity for the two coatings. The results are shown in figure $\mathbf{1 0}$ [28]. The values obtained for $e$ and $f$ are provided in table $\mathbf{3}$ with the associated errors. 

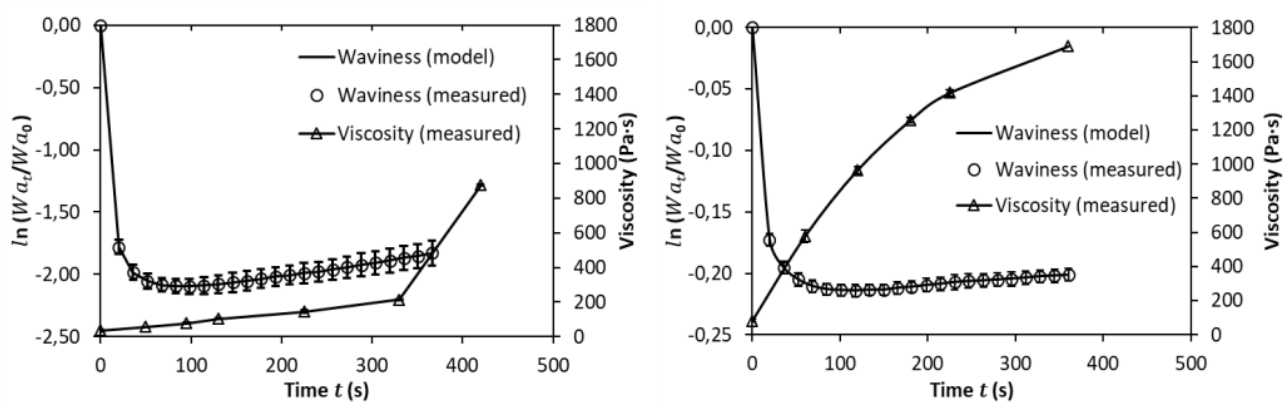

Figure 10. Comparison of waviness values obtained from experiments and calculated from the model (eq. 8, right hand side) as a function of time for model AF coating S2 (left) and the commercial AF coating (right). The viscosity profiles are also included. For both experiments and modeling, each data point is an average of five (model coating) and three repetitions (commercial coating) and the error bars represent the standard deviations.

Table 3. Estimated values and errors for the constants in eq. (8).

\begin{tabular}{|c|c|c|c|c|}
\hline \multirow[b]{2}{*}{ Constant } & \multicolumn{2}{|c|}{ Model coating S2 } & \multicolumn{2}{|c|}{ Commercial AF coating } \\
\hline & Estimated value & $\begin{array}{c}\text { Estimated } \\
\text { error }\end{array}$ & Estimated value & $\begin{array}{c}\text { Estimated } \\
\text { error }\end{array}$ \\
\hline $\bar{e}$ & 1.64 & \pm 0.02 & 1.40 & \pm 0.02 \\
\hline$f$ & $-34.68 \mathrm{~kg}^{\mathrm{e}} \cdot \mathrm{m}^{-\mathrm{e}} \cdot \mathrm{s}^{-\mathrm{e}-1}$ & $\underset{ }{ \pm 2.89 \mathrm{~kg}^{\mathrm{e}} \cdot \mathrm{m}^{-}}$ & $-23.25 \mathrm{~kg}^{\mathrm{e}} \cdot \mathrm{m}^{-\mathrm{e}} \cdot \mathrm{s}^{-\mathrm{e}-1}$ & $\underset{\mathrm{e}}{ \pm \frac{\mathrm{s}^{-\mathrm{e}-1}}{2.88 \mathrm{~kg}^{\mathrm{e}}} \cdot \mathrm{m}}$ \\
\hline
\end{tabular}

Kommenterede [SK5]: Please make room in the table for the errors to be on one line only so you do not have to "cut" the units in two.

Figure $\mathbf{1 0}$ shows that the modeling of waviness is in very good agreement with measured values for both coatings. It can be seen from table $\mathbf{3}$ that the values for $e$ and $f$ are somewhat different for the two coatings, which is probably attributed to the different waviness values (leveling performance) resulting from the different viscosity developments. In practice, viscosity behavior could be easily altered by additives present in the formulation. Therefore, it is not possible to match experimental values with 
modeling results without a separate fitting of the adjustable model parameters for a given coating. However, the model remains universal (at least for the coatings studied). It is not meaningful to compare the equation exponents obtained in this work with those of the Orchard equation, because the latter is based on an underlying assumption of no solvent evaporation and/or chemical curing taking place, as well as a constant coating viscosity.

\section{Conclusions}

Using an optical 3D profilometer in combination with an advanced rheometer and gravimetric evaporation rate experiments, transient data for leveling of coatings with simultaneous solvent evaporation and viscosity development could be obtained. Results showed that higher film thickness, shorter application wavelength, and lower coating viscosity led to better final leveling performance. By far, the most important parameter to consider for transient effects during leveling process is the coating viscosity.

The relationships between the final leveling performance and the coating parameters (initial average film thickness and wavelength) were correlated and both parameters were found to be of significant importance. Furthermore, a semi-empirical model could be fitted with very good agreement to the transient experimental data for both coatings. The two fitting parameters for the viscosity dependencies in the model were similar, but not identical for the two coatings. This was attributed to different rheology additives (thixotropic and wetting agents) present in the formulations.

Overall, the direct experimental approach can be a valuable tool in the optimization of leveling of coatings. 


\section{Acknowledgments}

The authors would like to thank Burak Ulusoy for his help with the model development work. Funding: This work was conducted under the partnership of Blue INNOship. Financial support from the Hempel Foundation to CoaST (The Hempel Foundation Coatings Science and Technology Centre) and from Innovation Fund Denmark, the Danish Maritime Fund, A.P. Møller - Mærsk A/S and Hempel A/S to the work is gratefully acknowledged.

\section{Data availability}

The raw data required to reproduce these findings are available to download from [https://data.mendeley.com/datasets/2b9ps9gv72/draft?a=ea509521-9fe6-4cb8-b6e0-2073666f369d].

The processed data required to reproduce these findings are available to download from [https://data.mendeley.com/datasets/2b9ps9gv72/draft?a=ea509521-9fe6-4cb8-b6e0-2073666f369d].

\section{References}

[1] W.S. Overdiep, The effect of a reduced solvent content of solvent- borne solution paints on film formation, Prog. Org. Coatings. 14 (1986) 1-21.

[2] A. Quach, Polymer coatings. Physics and Mechanics of leveling, Ind.Eng.Chem.Prod.Res.Develop. 12 (1973) 110-116. doi:10.1021/i360046a003.

[3] S.J. Dodge, Quantitative Measures of Leveling, J. Paint Technol. 44 (1972) 72-78.

[4] X. Wang, S.M. Olsen, E. Andres Martinez, K.N. Olsen, S. Kiil, Drag resistance of ship hulls: effects of surface roughness of newly applied fouling control coatings, coating water absorption, 
and welding seams, J. Coatings Technol. Res. 15 (2018) 657-669. doi:10.1007/s11998-0180054-7.

[5] N.D.P. Smith, S.E. Orchard, A.J. Rhind-Tutt, The Physics of Brushmarks, Surf. Coatings Int. 44 (1961) 618-633. doi:jglobal.jst.go.jp/en/public/201602000696958456.

[6] S.E. Orchard, On surface leveling in viscous liquids and gels, Appl. Sci. Res. Sect. A. 11 (1963) 451-464. doi:https://doi.org/10.1007/BF03184629.

[7] W.S. Overdiep, The leveling of paints, Prog. Org. Coatings. 14 (1986) 159-175. doi:https://doi.org/10.1016/0033-0655(86)80010-3.

[8] F. Seeler, C. Hager, O. Tiedje, M. Schneider, Simulations and experimental investigation of paint film leveling, J. Coatings Technol. Res. 14 (2017) 767-781. doi:10.1007/s11998-0179934-5.

[9] S.K. Wilson, The levelling of paint films, IMA J. Appl. Math. 50 (1993) 149-166. doi:10.1093/imamat/50.2.149.

[10] S.K. Wilson, The derivation and analysis of a model of the drying process of a paint film, Surf. Coatings Int. Part B Coatings Trans. 80 (1997) 162-167. doi:10.1007/BF02692636.

[11] S.D. Howison, J.A. Moriarty, J.R. Ockendon, E.L. Terrill, S.K. Wilson, A mathematical model for drying paint layers, J. Eng. Math. 32 (1997) 377-394. doi:10.1023/A:1004224014291.

[12] M.H. Eres, D.E. Weidner, L.W. Schwartz, Three-Dimensional Direct Numerical Simulation of Surface-Tension-Gradient Effects on the Leveling of an Evaporating Multicomponent Fluid, Langmuir. 15 (1999) 1859-1871. doi:10.1021/la980414u.

[13] M.H. Eres, L.W. Schwartz, R. V. Roy, Fingering phenomena for driven coating films, Phys. Fluids. 12 (2000) 1278-1295. doi:10.1063/1.870382.

[14] F. Durst, H. Raszillier, L.W. Schwartz, Theoretical and numerical modeling of coating flow on 
simple and complex substrates including rheology, drying and Marangoni effects, Adv. Coat. Dry. Thin Film. (2002) 105-128.

[15] R.V. Roy, A.J. Roberts, M.E. Simpson, A Lubrication Model of Coating Flows over a Curved Substrate in Space, J. Fluid Mech. 454 (2002) 235-261. doi:10.1017/S0022112001007133.

[16] L.W. Schwartz, R.R. Eley, A Mathematical Model for Three-dimensional Coating Flow with Thixotropy, in: 16th Int. Coat. Sci. Technol. Symp., Atlanta, 2012.

[17] S. Mahmoodi, H. Guoqing, M.N. Khajavi, Two-dimensional spin coating with a vertical centrifugal force and the effect of artificial gravity on surface leveling, J. Coatings Technol. Res. 13 (2016) 1123-1137. doi:10.1007/s11998-016-9823-3.

[18] M. Bosma, R. Brinkhuis, E. Rensen, R. Watson, A new method for the quantitative determination and prediction of sag and levelling in powder coatings, Prog. Org. Coatings. 72 (2011) 26-33. doi:10.1016/j.porgcoat.2011.01.010.

[19] C.A. Peters, M.E. Nichols, K.R.J. Ellwood, The evolution of surface texture in automotive coatings, J. Coatings Technol. Res. 8 (2011) 469-480. doi:10.1007/s11998-011-9333-2.

[20] X. Wang, C.E. Weinell, V. Tobar, S.M. Olsen, S. Kiil, Leveling measurements of antifouling coatings using an optical profilometer: effects of additives and solvent concentration and type, Submitted for publication to Prog. Org. Coatings, December 2018. Under review.

Slettet: , Slettet: unpublished results.

[21] D.M. Yebra, S. Kiil, K. Dam-Johansen, Antifouling technology - Past, present and future steps towards efficient and environmentally friendly antifouling coatings, Prog. Org. Coatings. 50 (2004) 75-104. doi:10.1016/j.porgcoat.2003.06.001.

[22] C.T. Patton, Paint Flow and Pigment Dispersion, second, Wiley-Interscience, New York, 1979.

[23] M. Lejars, A. Margaillan, C. Bressy, Fouling release coatings: A nontoxic alternative to biocidal antifouling coatings, Chem. Rev. 112 (2012) 4347-4390. doi:10.1021/cr200350v. 
[24] P.S. Granville, Drag-Characterization Method for Arbitrarily Rough Surfaces by Means of Rotating Disks, J. Fluids Eng. 104 (1982) 373-377.

[25] E. Holm, M. Schultz, E. Haslbeck, W. Talbott, A. Field, Evaluation of Hydrodynamic Drag on Experimental Fouling-release Surfaces, using Rotating Disks, Biofouling. 20 (2004) 219-226. doi:10.1080/08927010400011245.

[26] International Organization for Standardization, Geometrical product specifications (GPS)Surface texture: Areal-Part 2: Terms, definitions and surface texture parameters. (ISO 25178-2), 2012.

[27] International Organization for Standardization, Geometrical Product Specifications (GPS)Surface texture: Profile method-Terms, definitions and surface texture parameters. (ISO 4287), 1998.

[dataset] [28] X. Wang, Y. Huang, C.E. Weinell, S.M. Olsen, S. Kiil, Data for: Leveling kinetics of coatings with solvent evaporation and non-Newtonian rheology, Mendeley Data, v1, 2018. http://dx.doi.org/10.17632/2b9ps9gv72.1

[29] S. Kiil, Quantification of simultaneous solvent evaporation and chemcial curing in thermoset coatings, J. Coatings Technol. Res. 7 (2010) 569-586. doi:10.1007/s11998-010-9246-5. 